\title{
Antifungal activity of clinical Lactobacillus strains against Candida albicans biofilms: identification of potential probiotic candidates to prevent oral candidiasis
}

Rodnei Dennis Rossoni, Patrícia Pimentel de Barros, Janaina Araújo de Alvarenga, Felipe de Camargo Ribeiro, Marisol dos Santos Velloso, Beth Burgwyn Fuchs, Eleftherios Mylonakis, Antonio Olavo Cardoso Jorge \& Juliana Campos Junqueira

To cite this article: Rodnei Dennis Rossoni, Patrícia Pimentel de Barros, Janaina Araújo de Alvarenga, Felipe de Camargo Ribeiro, Marisol dos Santos Velloso, Beth Burgwyn Fuchs, Eleftherios Mylonakis, Antonio Olavo Cardoso Jorge \& Juliana Campos Junqueira (2018) Antifungal activity of clinical Lactobacillus strains against Candida albicans biofilms: identification of potential probiotic candidates to prevent oral candidiasis, Biofouling, 34:2, 212-225, DOI: 10.1080/08927014.2018.1425402

To link to this article: https://doi.org/10.1080/08927014.2018.1425402

+ View supplementary material 둔

Submit your article to this journal $2 \pi$
曲 Published online: 30 Jan 2018.

III Article views: 1138 


\title{
Antifungal activity of clinical Lactobacillus strains against Candida albicans biofilms: identification of potential probiotic candidates to prevent oral candidiasis
}

\author{
Rodnei Dennis Rossonia (D), Patrícia Pimentel de Barros ${ }^{a}$, Janaina Araújo de Alvarengaa, \\ Felipe de Camargo Ribeiro , Marisol dos Santos Velloso ${ }^{a}$, Beth Burgwyn Fuchs ${ }^{b}$, Eleftherios Mylonakis ${ }^{b}$, \\ Antonio Olavo Cardoso Jorge ${ }^{\mathrm{a}}$ and Juliana Campos Junqueira ${ }^{\mathrm{a}}$
}

aDepartment of Biosciences and Oral Diagnosis, Institute of Science and Technology, UNESP - Univ Estadual Paulista, Sao Jose dos Campos, Brazil; bivision of Infectious Diseases, Rhode Island Hospital, Alpert Medical School of Brown University, Providence, RI, USA

ABSTRACT

This study isolated Lactobacillus strains from caries-free subjects and evaluated the inhibitory effects directly on three strains of $C$. albicans, two clinical strains and one reference strain. Thirty Lactobacillus strains were isolated and evaluated for antimicrobial activity against in vitro C. albicans biofilms. L. paracasei 28.4, L. rhamnosus 5.2 and L. fermentum 20.4 isolates exhibited the most significant inhibitory activity against C. albicans. Co-incubation between these microorganisms resulted in deterrence of biofilm development and retardation of hyphal formation. The hindrance of biofilm development was characterized by the downregulated expression of C. albicans biofilmspecific genes (ALS3, HWP1, EFG1 and CPH1). L. paracasei 28.4, L. rhamnosus 5.2 and L. fermentum 20.4 demonstrated the ability to exert antifungal activity through the inhibition of $C$. albicans biofilms.
ARTICLE HISTORY

Received 11 September 2017

Accepted 3 January 2018

\section{KEYWORDS}

Biofilm; mycology; pathogenesis; Candida albicans; Lactobacillus

\section{Introduction}

Candida albicans is a commensal yeast commonly found in the oral cavity of humans, isolated from $\sim 62 \%$ of healthy individuals. This dimorphic fungus is considered an opportunistic pathogen that can cause severe and recurrent infections in the mucosa and even fatal systemic infections (Sellam and Whiteway 2016; Noble et al. 2017). The impact of candidiasis on human health has significantly increased in recent decades, in particular because of the growing number of immunocompromised patients resulting from the acquired immunodeficiency syndrome (AIDS) epidemic, organ transplantation, and cancer chemotherapies that affect the human microbiome (Sellam and Whiteway 2016).

Infections in the oral cavity by Candida spp., such as pseudomembranous, erythematous, and hyperplastic candidiasis, occur due to the formation of biofilms composed of yeast and hyphae (da Silva Dantas et al. 2016; Millsop and Fazel 2016). Whilst C. albicans can exist in a planktonic form, it inhabits humans predominantly as biofilms. Structured biofilms are three-dimensional microbial communities attached to a solid surface, embedded in a matrix of extracellular polymeric substances (Darrene and Cecile 2016; Tsui et al. 2016). Due to the greater resistance of biofilms to antifungals and host defenses compared to planktonic cultures, biofilm formation is an important virulence attribute of C. albicans (Alcazar-Fuoli and Mellado 2014). Since biofilms can be so difficult to eradicate due to the induction of efflux pump expression, physical barring of antimicrobial therapeutic agents and the harboring of persister cells that lead to chronic infections, it is important to develop biofilm prevention methods for susceptible individuals. Several antimicrobial agents and new therapeutic strategies, such as the use of probiotics in the oral cavity, have been investigated to control oral biofilms (do Carmo et al. 2016; Oliveira et al. 2016; Salas-Jara et al. 2016; Schwendicke et al. 2017).

The World Health Organization defines probiotics as live microorganisms that confer health benefits to the host when administered in adequate amounts. These benefits are mainly due to the regulation of the resident microbiota and modulation of the immune system by activation of lymphoid cells. Several microorganisms have been used as probiotics, including Bifidobacterium, Saccharomyces, Bacillus, and Lactobacillus (Guarner et al. 2012; Herbel

CONTACT Rodnei Dennis Rossoni dennisrossoni@hotmail.com

(4) Supplemental material for this paper is available online at https://doi.org/10.1080/08927014.2018.1425402

(c) 2018 Informa UK Limited, trading as Taylor \& Francis Group 
et al. 2013; Vilela et al. 2015). Lactobacilli are bacteria that naturally colonize the oral cavity and gastrointestinal tract of healthy humans. In the oral cavity, certain strains of lactobacilli can cause caries through their acidogenic and aciduric characteristics and are frequently detected in lesions of deep cavities. However, some studies suggest an additional beneficial role for oral lactobacilli. Lactobacillus paracasei, Lactobacillus plantarum, and Lactobacillus rhamnosus strains isolated from caries-free individuals inhibited the in vitro growth of oral pathogens species such as Streptococcus mutans and Streptococcus sobrinus more efficiently than the Lactobacillus strains isolated from patients with active caries (Simark-Mattsson et al. 2007; Belda-Ferre et al. 2012; Million and Raoult 2013).

Moreover, previous studies in the literature showed that some probiotic strains of Lactobacillus inhibited C. albicans biofilm formation through the production of bacteriocins, immunomodulatory effects, or even by mechanical inhibition of adhesion receptors (Orsi et al. 2014; Vilela et al. 2015; Matsubara et al. 2016; Wannun et al. 2016; Ribeiro et al. 2017). Despite the large number of studies with probiotics against $C$. albicans biofilms, it is still unclear whether the inhibition of fungal biofilm development is dependent on a direct interaction with probiotic bacterial cells or the secretion of factors produced by the probiotics (ie supernatants), and it is also unknown which of the C. albicans genes involved in this prokaryote-eukaryote association can affect and destabilize biofilm formation.

Despite growing interest in probiotics in the past few years, most probiotic strains used and known were isolated from the gastrointestinal tract and have become 'standard strains' (Simark-Mattsson et al. 2007; Rivera-Espinoza and Gallardo-Navarro 2010; Shanahan et al. 2012). The present authors' studies are based on the hypothesis that the oral cavity of healthy individuals may house alternative beneficial Lactobacillus isolates with inhibitory activity against fungal pathogens. Healthy oral microbiota contains a highly diverse species population, which results in balance, functional redundancy, and resistance to disease (Grady et al. 2016). Therefore, resident oral microbiota from healthy individuals could provide new strains with probiotic efficacy (Belda-Ferre et al. 2012; Shanahan et al. 2012; Olle 2013).

Thus, the aim of this study was to isolate and to identify Lactobacillus isolates from the oral cavity of caries-free individuals and evaluate their antifungal effects on biofilms of C. albicans, using three fungal strains, one reference and two clinics. In addition, this study sought to elucidate the mechanisms that Lactobacillus isolates use to disrupt Candida biofilms by studying the supernatant filtrate of Lactobacillus cultures and the effect on the gene expression of C. albicans.

\section{Materials and methods}

\section{Subjects}

The study group comprised 41 caries-free individuals (mean age $19 \pm 2.1$ years) with no history of systemic disease or antibiotic therapy one month prior to sampling. All patients agreed to participate in the study by signing the informed consent form approved by the Research Ethics Committee of the Institute of Science and Technology, UNESP - Univ Estadual Paulista (protocol 560.479).

Participants were recruited from February to August 2014 and subjected to an oral clinical examination. The presence of a cavity and/or restorations due to caries was considered an exclusion factor for the study. The same examiner performed all clinical evaluations.

\section{Sampling of saliva and Lactobacillus identification}

All subjects were investigated for the presence of lactobacilli in saliva. Saliva samples were collected by oral rinses in $10 \mathrm{ml}$ of phosphate buffered saline (PBS, $\mathrm{pH}$ 7.2) for $1 \mathrm{~min}$. The samples were centrifuged for $10 \mathrm{~min}$ at 5,000 RPM and the supernatant was discarded. Next, $2.5 \mathrm{ml}$ of PBS were added to the pellet. Tenfold serial dilutions were carried out, and aliquots of $100 \mu \mathrm{l}$ were seeded onto ManRogosa-Sharpe (MRS) agar (Difco, Detroit, MI, USA) and Rogosa SL agar (Difco) using the conventional pour plate methodology. The plates were incubated for $72 \mathrm{~h}$ under microaerobic conditions with $10 \% \mathrm{CO}_{2}$ at $37^{\circ} \mathrm{C}$.

After incubation of the plates in microaerobic conditions $\left(10 \% \mathrm{CO}_{2}\right)$ for $72 \mathrm{~h}$, colonies with different morphologies (MRS agar) and characteristic discoid colonies (Rogosa SL agar) were Gram stained, and only the Grampositive and rod-shaped bacteria were isolated for identification using molecular methods. The chromosomal DNA of each isolate was extracted using a PureLink Genomic DNA kit (Invitrogen, Carlsbad, CA, USA) according to the manufacturer's instructions. PCR amplification of the intergenic segment between the $16 \mathrm{~S}$ and $23 \mathrm{~S}$ rRNA subunits was carried out as described by Song et al. (2000). For this experiment, reference samples of Lactobacillus were included as positive controls for the PCR reaction (Lactobacillus plantarum ATCC 8014, Lactobacillus paracasei subsp. paracasei ATCC 335 and Lactobacillus rhamnosus ATCC 9595).

\section{Strains and growth conditions}

In this study, the reference strain C. albicans ATCC 18804 was used, as well as two clinical strains, C. albicans 60 (CA60) and C. albicans 230S (CA230S) from the Laboratory of Microbiology of the Institute of Science and Technology of São José dos Campos/UNESP 
(São Paulo State University). The clinical strains were isolated from oropharyngeal candidiasis lesions of HIVpositive patients from Emílio Ribas Infectology Institute (Instituto de Infectologia Emílio Ribas, São Paulo, Brazil), with the approval of the Ethics Committee (Protocol 051/2009-PH/CEP). In addition, 30 clinical isolates of Lactobacillus were identified according to the section above. The clinical strains of Candida were isolated and identified according to Junqueira et al. (2012).

All C. albicans strains were cultured for $18 \mathrm{~h}$ at $37^{\circ} \mathrm{C}$ in yeast nitrogen base broth (YNB; Difco) supplemented with $100 \mathrm{mM}$ glucose. Lactobacillus isolates were cultured in Lactobacillus MRS broth (MRS broth; Difco) for $24 \mathrm{~h}$ at $37^{\circ} \mathrm{C}$ under microaerophilic conditions. The suspension densities were determined with a spectrophotometer (B582, Micronal, Sao Paulo, Brazil) and diluted to a concentration of $10^{7}$ cells $\mathrm{ml}^{-1}$. The quantification of the cell number of the inoculum was confirmed by counting CFU ml ${ }^{-1}$ after plating in Sabouraud dextrose agar (SDA; HiMedia, Mumbai, India) with chloramphenicol $\left(0.05 \mathrm{~g} \mathrm{l}^{-1}\right)$ for C. albicans and MRS agar (Difco) for Lactobacillus.

The preparation of the Lactobacillus supernatant was performed according to Ribeiro et al. (2017). An inoculum of $1 \mathrm{ml}$ of the standard suspension was seeded into $6 \mathrm{ml}$ of MRS broth and incubated at $37^{\circ} \mathrm{C}$ for $24 \mathrm{~h}$ under microaerophilic conditions. After this incubation, the broth was centrifuged (5,000 RPM for $10 \mathrm{~min})$ and filtered with a $0.22 \mu \mathrm{m}$ pore size membrane (MFS, Dublin, CA, USA).

\section{Antibacterial activity of Lactobacillus strains against $\mathrm{C}$. albicans in planktonic cultures}

The antibacterial activities of the Lactobacillus strains against C. albicans ATCC 18804 in planktonic cultures were assessed according to the methodology previously described (Lin et al. 2015) with some modifications. Standardized cell suspensions of C. albicans and Lactobacillus were prepared as described above. Next, $250 \mu \mathrm{l}$ of a C. albicans suspension and $250 \mu \mathrm{l}$ of a Lactobacillus suspension (or culture filtrate) were mixed with $1.5 \mathrm{ml}$ of BHI broth. In the control group, microbial suspensions of Lactobacillus were replaced by PBS. All the cultures were incubated at $37^{\circ} \mathrm{C}$ for $24 \mathrm{~h}\left(5 \% \mathrm{CO}_{2}\right)$. After incubation, the cultures were diluted and plated on Sabouraud dextrose agar (Difco) supplemented with chloramphenicol $\left(0.05 \mathrm{~g} \mathrm{l}^{-1}\right)$ for $C$. albicans growth. The plates were incubated at $37^{\circ} \mathrm{C}$ for $48 \mathrm{~h}$ and the number of colony-forming units $\left(\mathrm{CFU} \mathrm{ml}{ }^{-1}\right)$ were determined. This assay was performed as three independent experiments with four separate cultures per group.

\section{Biofilm formation}

The anti-biofilm activity of the Lactobacillus strains were tested against C. albicans ATCC 18004, CA60 and CA230S. This test was performed in 96-well microtiter plates (TPP", Trasadingen, Switzerland) following the methodology described by Vilela et al. (2015) and Ribeiro et al. (2017), with some modifications. Briefly, $100 \mu \mathrm{l}$ of all C. albicans standard suspension $\left(10^{7}\right.$ cells $\left.\mathrm{ml}^{-1}\right)$ were pipetted into 96-well microtiter plates and the plates were placed on a 75-rpm shaking incubator (Quimis, Diadema, São Paulo, Brazil) at $37^{\circ} \mathrm{C}$ for $90 \mathrm{~min}$. Each well was washed twice with PBS, and $50 \mu \mathrm{l}$ of Lactobacillus cells or $50 \mu \mathrm{l}$ of supernatant were added into the wells of each plate. For the control groups, $50 \mu \mathrm{l}$ of PBS or MRS broth were added. To promote biofilm growth, $70 \mu \mathrm{l}$ of YNB supplemented with $100 \mathrm{mM}$ glucose and $30 \mu \mathrm{l}$ of BHI broth were added to each well. The plate was incubated for $48 \mathrm{~h}$ at $37^{\circ} \mathrm{C}$ with shaking at $75 \mathrm{rpm}$. The liquid medium was replaced after $24 \mathrm{~h}$.

\section{Analysis of biofilms by CFU counting}

The quantification of the number of viable cells in the biofilms was based on the methodologies described by Thein et al. (2006) and Vilela et al. (2015). After 48 h, plate contents were aspirated, and the wells were washed twice with PBS. Subsequently, $200 \mu$ of PBS were added to each well, and the biofilm was disrupted using an ultrasonic homogenizer (Vibra-Cell, Sonics \& Materials, Inc., Newtown, CT, USA) for $30 \mathrm{~s}$ with $25 \%$ amplification. After homogenization, serial dilutions of the biofilm suspension were performed, and $100 \mu \mathrm{l}$ aliquots of these dilutions were inoculated into Petri dishes containing SDA. The plates were incubated at $37^{\circ} \mathrm{C}$ for $48 \mathrm{~h}$. After incubation, the colonies were counted to calculate the $\mathrm{CFU} \mathrm{m} \mathrm{m}^{-1}$ values. The cellular quantification was performed with $n=10$ biofilm replicates per group.

\section{Analysis of biofilms by total biomass quantification}

After biofilm formation, the biofilm biomass was quantified utilizing an assay previously described by Peeters et al. (2008), with modifications. For fixation of the biofilms, $100 \mu \mathrm{l}$ of $99 \%$ methanol were added to the wells (Sigma-Aldrich, São Paulo, Brazil). After $15 \mathrm{~min}$, the supernatants were removed and the plates were air dried. Then, $100 \mu \mathrm{l}$ of a $1 \%$ crystal violet (CV) solution were added to all wells. After $20 \mathrm{~min}$, the residual CV solution was removed by washing with PBS. Finally, bound CV was released by adding $150 \mu \mathrm{l}$ of $33 \%$ acetic acid (SigmaAldrich). The absorbance was measured at $540 \mathrm{~nm}$. All steps were carried out at room temperature. The $\mathrm{CV}$ assay 
was performed as two independent experiments with $n=6$ biofilms per group.

\section{Analysis of biofilms by scanning electron microscopy} (SEM)

Acrylic resin disks, measuring $8 \mathrm{~mm}$ in diameter, were placed on a 24-well plate for biofilm formation, following the methodology of Barbosa et al. (2016). After biofilm formation, the specimens were fixed in $1 \mathrm{ml}$ of $2.5 \%$ glutaraldehyde for $1 \mathrm{~h}$. The specimens were then dehydrated in an increasing ethanol series (10, 25, 50, 75 and 90\%) for $20 \mathrm{~min}$ each, followed by immersion in $100 \%$ alcohol for $1 \mathrm{~h}$. The plates were kept in an oven at $37^{\circ} \mathrm{C}$ for $24 \mathrm{~h}$ to permit total drying of the specimens.

After drying, the specimens were transferred to aluminum stubs and sputter coated with gold for $160 \mathrm{~s}$ at 40 mA (Denton Vacuum Desk II, Denton Vaccum LLC, Moorestown, NJ, USA). The specimens were examined and imaged using a JEOL JSM-5600 scanning electron microscope (JEOL USA, Inc., Peabody, MA, USA) at the Institute of Science and Technology, UNESP - Univ Estadual Paulista. These experiments were performed at two different times with $n=3$ biofilms per group.

\section{Analysis of $\mathrm{C}$. albicans gene expression using RT-PCR}

Biofilms were formed in 24-well microtiter plates (TPP $\left.{ }^{\circledast}\right)$ using the same concentrations and conditions for biofilm formation described above. After biofilm formation, $1 \mathrm{ml}$ of TRIzol $^{\oplus}$ (Ambion, Inc., Carlsbad, CA, USA) was added to each well to remove and collect the biofilm. The yeast/ TRIzol $^{\circledR}$ suspension was added to a $2 \mathrm{ml}$ microtube and incubated at room temperature for $10 \mathrm{~min}$. Subsequently, $200 \mu \mathrm{l}$ of chloroform were added (Sigma-Aldrich, St Louis, MO, USA), and the microtubes were centrifuged at $12,000 \times \mathrm{g}$ for $15 \mathrm{~min}$ at $4^{\circ} \mathrm{C}$. The supernatants were transferred to new microtubes, and $500 \mu \mathrm{l}$ of isopropanol (Sigma-Aldrich) were added. After centrifugation, the resulting sediment was washed with 70\% ethanol (SigmaAldrich), centrifuged again and resuspended in $50 \mu \mathrm{l}$ of RNA storage buffer (Ambion, Inc.). The RNA concentration, purity and quality were measured using a NanoDrop 2000 Spectrophotometer (Thermo Fisher Scientific Inc., Wilmington, DE, USA) and agarose gel electrophoresis (Invitrogen $^{\mathrm{TM}}$, Carlsbad, CA, USA). The gel was stained with ethidium bromide (Invitrogen ${ }^{\mathrm{TM}}$ ) and visualized on a transilluminator.

The total extracted RNA $(1 \mu \mathrm{g})$ was treated with DNase-I (TURBO DNase Treatment and Removal Reagents, Ambion, Inc.) and was transcribed into complementary DNA (cDNA) using the SuperScript III First-Strand
Synthesis SuperMix Kit for qRT-PCR (Invitrogen ${ }^{\mathrm{TM}}$ ) according to the manufacturer's recommendations.

The primers for the genes analyzed in the present study were described and used as indicated by Nailis et al. (2010), Hnisz et al. (2012) and Granger (2012). The primer specificity was confirmed for $C$. albicans (Barros et al. 2016).

Transcribed cDNAs were amplified for the relative quantification of the ALS3, HWP1, CPH1,EFG1, and $Y W P 1$ gene expression levels in relation to the concentration of the reference gene $(R P P 2 B)$. In the present study, four reference genes (RPP2B, PMA1, RIP1, and LSC2) were tested in all experimental groups. The results were analyzed at http://www.leonxie.com/referencegene.phpe and the reference gene chosen was RPP2B.

The qPCR method was used to evaluate the amount of the cDNA product in the exponential phase of the amplification reaction. The SYBR Green fluorophore (Platinum SYBR $^{\circ}$ Green qPCR SuperMix-UDG Applied Biosystems, Framingham, MA, USA) was used as the detection system as recommended by the manufacturer. As a negative control for the reaction, all reagents except cDNA were added to the last wells of the plates and the wells were sealed with optical adhesive (Invitrogen ${ }^{\mathrm{TM}}$ ). Next, plates were placed in a StepOnePlus ${ }^{\text {mm }}$ System (Applied Biosystems), and the following cycling parameters were used: $50^{\circ} \mathrm{C}$ for $2 \mathrm{~min}$, followed by an initial denaturation at $95^{\circ} \mathrm{C}$ for $2 \mathrm{~min}, 40$ cycles of $95^{\circ} \mathrm{C}$ for $15 \mathrm{~s}$ and $60^{\circ} \mathrm{C}$ for $30 \mathrm{~s}$. After the end of the last cycle, the samples were subjected to dissociation (melting) curve analysis. The absence of any bimodal curve or abnormal amplification signal was observed and analyzed every $0.1^{\circ} \mathrm{C}$. The $2^{-\Delta \Delta C T}$ method was used to analyze the relative changes in gene expression from the quantitative RT-PCR experiment (Livak and Schmittgen 2001).

\section{Statistical analysis}

The Student's $t$-test was used to compare the CFU ml ${ }^{-1}$ results from the in vitro biofilm formation assay, the $\mathrm{CV}$ assay, and the relative quantification of gene expression. All analyses were performed using the GraphPad Prism 6 Program (GraphPad Software, Inc., La Jolla, CA, USA) and a level of significance of $5 \%$ was adopted.

\section{Results}

Among the 41 caries-free individuals evaluated, 27 (66\%) had cultures that were positive for Lactobacillus in the oral cavity. From these individuals, 30 clinical isolates of Lactobacillus were identified including the following species: Lactobacillus paracasei (23), Lactobacillus rhamnosus (5) and Lactobacillus fermentum (2). The distribution of the identified species is shown in Table 1. 
Table 1. Clinical strains of Lactobacillus identified in this study.

\begin{tabular}{lc}
\hline Species & Strain designation \\
\hline L.paracasei & 1.1 \\
L.paracasei & 3.1 \\
L.paracasei & 4.2 \\
L.rhamnosus & 5.2 \\
L.paracasei & 6.2 \\
L.paracasei & 7.5 \\
L.paracasei & 8.4 \\
L.paracasei & 10.5 \\
L.paracasei & 11.6 \\
L.rhamnosus & 13.1 \\
L.fermentum & 14.5 \\
L.paracasei & 15.8 \\
L.paracasei & 16.4 \\
L.paracasei & 17.1 \\
L.rhamnosus & 19.3 \\
L. rhamnosus & 19.9 \\
L.paracasei & 20.3 \\
L.fermentum & 20.4 \\
L.paracasei & 21.4 \\
L.paracasei & 23.4 \\
L.paracasei & 24.1 \\
L.paracasei & 25.4 \\
L.paracasei & 26.1 \\
L.paracasei & 27.1 \\
L.paracasei & 28.4 \\
L.paracasei & 30.1 \\
L.fermentum & 31.4 \\
L.rhamnosus & 36.4 \\
L.paracasei & 37.1 \\
L.paracasei & 39.2 \\
\hline
\end{tabular}

First, all the strains were screened for antibacterial activity against C. albicans ATCC 18804 using planktonic cultures. For this purpose, each Lactobacillus strain was co-cultured with C. albicans for $24 \mathrm{~h}$. Moreover, the indirect effects of Lactobacillus were analyzed using only the Lactobacillus culture filtrate that was obtained after its growth in MRS broth. To determine whether the MRS broth of the Lactobacillus culture could exert an effect on $C$. albicans and interfere with the results, a control group consisting only of $C$. albicans and MRS broth was included. After $24 \mathrm{~h}$, the growth of C. albicans was evaluated by counting the CFU ml${ }^{-1}$.

Among the 30 Lactobacillus strains analyzed, 26 (86\%) showed antibacterial activity against $C$. albicans. L. paracasei 30.1, 37.1 and 39.2 strains and L. rhamnosus strain 36.4 were the strains that had no inhibitory effects on C. albicans ATCC 18804. For other Lactobacillus strains, the percentage reductions in C. albicans growth ranged from 82 to $98 \%$ depending on the strain analyzed (Figure $1 \mathrm{~A})$.

In addition, $86 \%$ of the Lactobacillus strains had an inhibitory effect on C. albicans ATCC 18804 growth when only their supernatant was placed in contact with C. albicans (Figure 1A). The results showed that the MRS broth used to prepare the Lactobacillus supernatant did not interfere with the growth of C. albicans. The CFU ml ${ }^{-1}$ count of C. albicans was $8.43 \mathrm{Log}$ for the C. albicans + PBS control group and $8.36 \mathrm{Log}$ for the C. albicans + MRS broth control group (Student's $t$-test, $p=0.8927)$. These data indicated that the anti-Candida activity of the supernatant could be attributed to some metabolites produced by the Lactobacillus strains.

Based on these results, these strains were selected for the in vitro C. albicans biofilm studies. 30 clinically derived isolates were screened to select those which were most capable of reducing the CFUs of $C$. albicans ATCC 18804 in the mixed biofilms (C. albicans and Lactobacillus) in comparison to the single biofilms (only C. albicans, control group). The growth of C. albicans ATCC 18804 was inhibited by most Lactobacillus isolates when interacting directly with the Lactobacillus cells and even with the supernatant of Lactobacillus cultures (Figure 1B). To verify whether the composition of the MRS broth of the Lactobacillus cultures could affect $C$. albicans and interfere with the assay testing the supernatants of these lactic acid bacteria, another control group was included, C. albicans and MRS broth. The results showed that addition of MRS broth alone to the supernatant did not inhibit the growth of C. albicans for any of the studied strains (Supplemental material Table 1).

The three isolates that exhibited the highest antifungal activity against C. albicans ATCC 18804 were L. rhamnosus 5.2, L. fermentum 20.4 and $L$. paracasei 28.4. The recovered number of $C$. albicans CFUs after exposure to the Lactobacillus strains were subjected to statistical analysis and the results are presented in Figure 2A. C. albicans exhibited a significant decrease in growth after interaction with Lactobacillus cells for the three analyzed bacterial isolates. Exposure to L. rhamnosus 5.2 resulted in a 0.5 Log reduction in the number of recovered fungal CFUs $(p=0.0001)$. This was followed by a $0.4 \mathrm{Log}$ reduction in fungi after exposure to L. fermentum 20.4 ( $p=0.0001)$. The most significant reduction in the number of recovered fungal CFUs was attributed to $L$. paracasei 28.4 that reduced fungal cells by $0.72 \log (p=0.0001)$. Lactobacillus supernatant decreased the $C$. albicans growth by $0.4 \mathrm{Log}$ for L. rhamnosus $5.2(p=0.0001), 0.6 \log$ for L. fermentum $20.4(p=0.0001)$ and $0.6 \log$ for $L$. paracasei 28.4 $(p=0.0001)$.

The biofilms associated with $L$. paracasei strain 28.4 showed the best reduction in C. albicans ATCC 18804 cells. Then, this Lactobacillus strain was tested with two clinical isolates of C. albicans, CA60 and CA230S, as previous studies demonstrated that these fungal isolates exhibited high in vitro expression of virulence genes (ALS1, ALS3, HWP1, BCR1, EFG1, TEC1, SAP5, PLB2, and LIP9) and pathogenicity in an animal model (de Barros et al. 2017). In biofilms with $C$. albicans clinical strains, exposure to L. paracasei 28.4 cells resulted in a 0.77 Log reduction in the number of recovered fungal CFUs $(p=0.0001)$ for CA60 and 1.20 Log reduction for CA230S $(p=0.0001)$. 


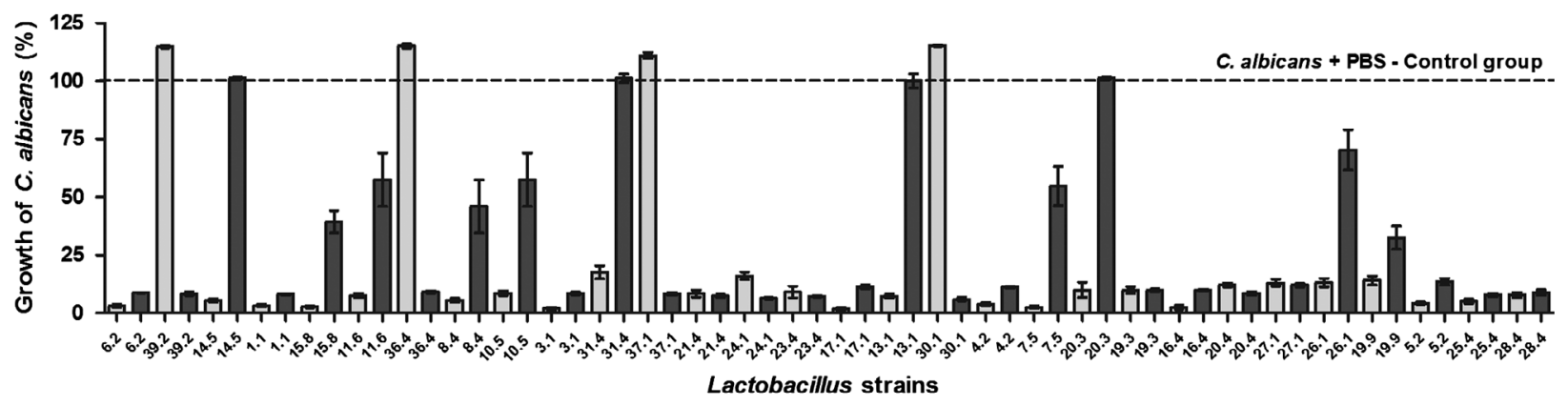

(B) Biofilm growth

C. albicans + cells of Lactobacillus interaction groups

C. albicans + supernatant of Lactobacillus interaction groups

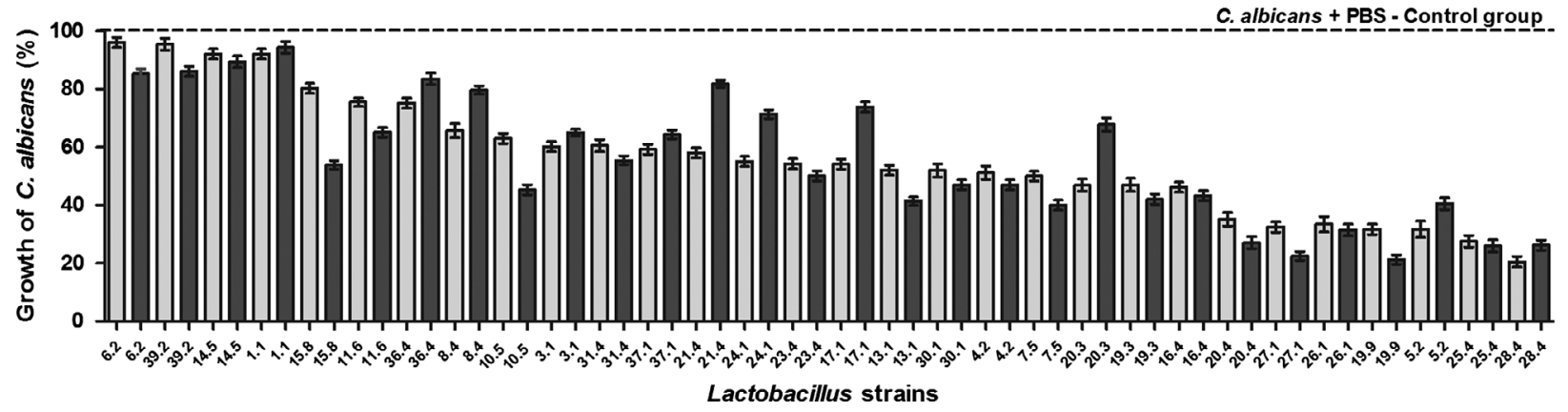

Figure 1. (A) Growth percentages of C. albicans ATCC 18804 obtained by counting the CFU $\mathrm{ml}^{-1}$ in planktonic culture. (B) Growth percentages of $C$. albicans ATCC 18804 obtained by counting the CFU biofilm ${ }^{-1}$ in a biofilm model. Percentage reduction expressed as mean values (CFU ml ${ }^{-1}$ or CFU biofilm ${ }^{-1}$ ) show the viability of $C$. albicans in the cell and supernatant groups of the Lactobacillus spp. in relation to the untreated control group.

This was followed by a 0.96 and $1.92 \mathrm{Log}$ reduction in the fungus after exposure to $L$. paracasei 28.4 supernatant $(p=0.0001)$ for CA60 CA230S, respectively (Figure 2B).

To quantify the difference in the total amount of biofilm present among co-cultured samples, the biofilms were stained with CV. Prioritizing the Lactobacillus isolates that inhibited growth most significantly through the reduction in the number of cells present in the biofilm, the isolates L. rhamnosus 5.2, L. fermentum 20.4 and L. paracasei 28.4 were used to determine the effect on quantitative biofilms C. albicans ATCC 18804. The biofilms formed by C. albicans ATCC 18804 in the presence of Lactobacillus cells exhibited a significant reduction compared to the control group that lacked Lactobacillus cells. In relation to the indirect effects of Lactobacillus on C. albicans ATCC 18804, the presence of Lactobacillus supernatant also reduced the total biofilm formed by $C$. albicans (Figure 3A). Regarding L. paracasei strain 28.4 in association with clinical strains of C. albicans, the biofilms formed by C. albicans in the presence of Lactobacillus cells or its supernatant exhibited a significant reduction compared to the control group of C. albicans (Figure 3B).
The biofilms formed were also evaluated by SEM, enabling observation of mature biofilm formation on acrylic resin disks after incubation for $48 \mathrm{~h}$. The $C$. albicans cells observed in the biofilms showed morphological variations according to the experimental group. The biofilms formed by C. albicans in the absence of Lactobacillus were characterized by the presence of numerous yeasts and hyphae for all tested strains (Figure 4A). In mixed microbe populations involving co-incubation of C. albicans with Lactobacillus isolates, the adherence of bacterial cells to C. albicans yeasts was verified and also inhibition of hyphal formation (Figure 4B). However, for the biofilms composed of C. albicans and Lactobacillus supernatant, a reduction in yeast was observed, together with a lack of hyphal formation and alterations in the morphology of the fungal cells (Figure 4C).

Therefore, SEM images confirmed the results obtained from the CFU count and CV assays, showing that the cells and supernatants of Lactobacillus isolates influenced C. albicans viability and reduced the total amount of biofilm. In addition, SEM showed that Lactobacillus strains were capable of inhibiting C. albicans filamentation. 
(A)

\section{C. albicans ATCC strain}

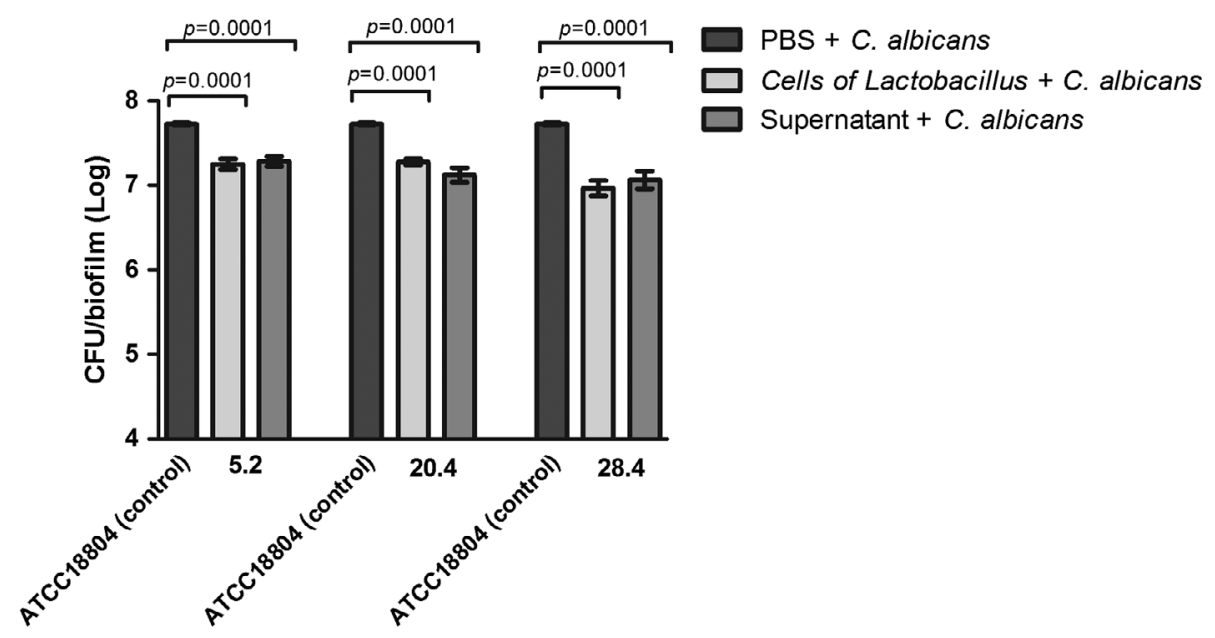

(B)

\section{C. albicans clinical strains}

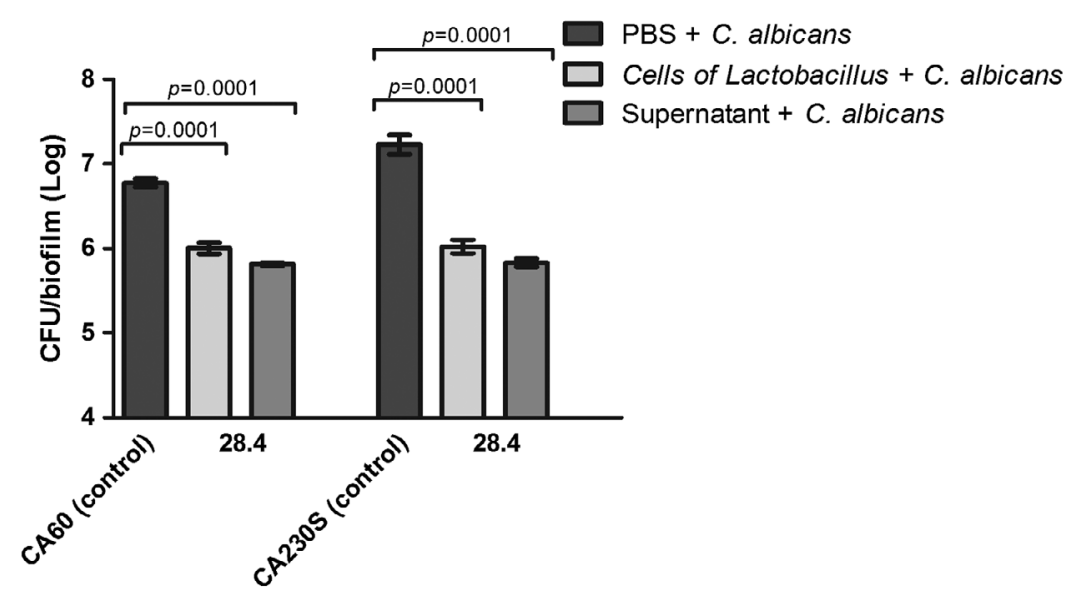

Figure 2. CFU counting of C. albicans in biofilms formed in vitro. Mean and SD for the number of CFU ml-1 of C. albicans (Log) in the control group biofilm (C. albicans + PBS) and in the groups with Lactobacillus cells or their supernatant. (A) Interaction of $C$. albicans ATCC 188804 and Lactobacillus. There was a statistically significant difference between all analyzed groups $(p=0.0001)$. (B) Interaction of C. albicans clinical strains (CA60 and CA230S) and Lactobacillus. There was a statistically significant difference between all the groups analyzed $(p=0.0001)$. The Student's $t$-test was used.

To elucidate the mechanisms used by Lactobacillus strains to inhibit C. albicans biofilms this study was extended to analyze $C$. albicans gene expression, concentrating on genes known to be important to biofilm formation. The expression levels of the adhesion genes (ALS3, $H W P 1$, and $Y W P 1)$ and transcriptional regulatory genes (EFG1 and CPH1) were quantified in C. albicans cells from single and mixed biofilms using qPCR (Figure 5).

The largest reductions in the expression of the analyzed C. albicans genes were obtained with the 28.4 strain. For the C. albicans ATCC 18804, the adhesion (ALS3) and filamentation (HWP1) genes were the most affected, achieving a 333- and 100-fold decrease in the C. albicans biofilms associated with 28.4 cells, respectively. Regarding the biofilms treated with 28.4-strain supernatant, 33- and
20 -fold decreases in the ALS3 and HWP1 genes, respectively, were verified. This reduction was also observed with the clinical strains of $C$. albicans used in this study for association with Lactobacillus cells or their supernatant. For the CA60 strain, a significant fold change in the genes was observed: ALS3 (5,000-fold decrease), HWP1 (10,000fold decrease) and $\mathrm{CPH} 1$ (500-fold decrease). Regarding CA230S, the most downregulated genes were EFG1 (5.88fold decrease) and HWP1 (3.84-fold decrease).

Regarding YWP1 that is a marker of the yeast form of C. albicans linked covalently to glucans of the wall matrix, all groups with Lactobacillus strains (cells or supernatant) were positively regulated to this gene compared to the C. albicans control group. The largest increases in the expression of this gene were obtained with the supernatant 


\section{C. albicans ATCC strain}

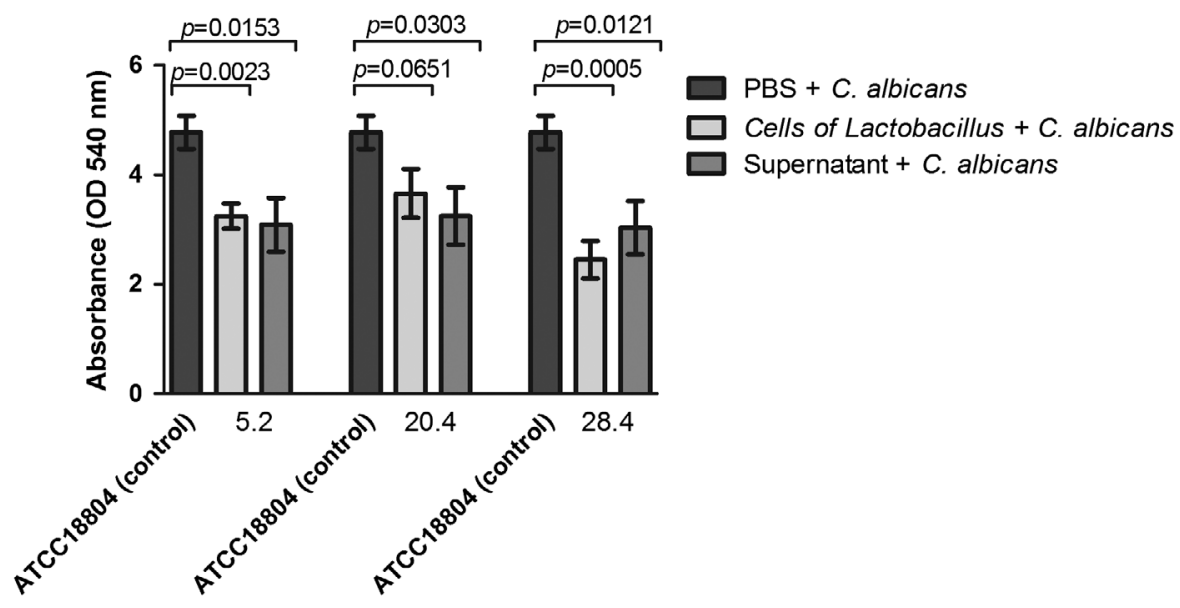

(B) C. albicans clinical strains

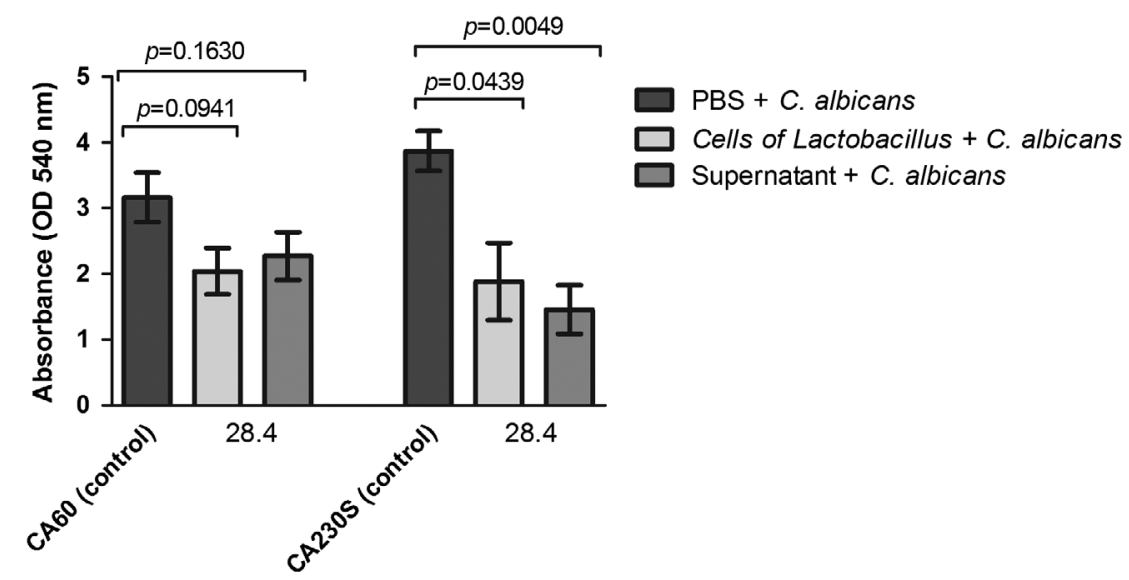

Figure 3. Evaluation of biomass formed by biofilms of C. albicans. Mean and SD of the absorbance value of control group biofilms (C. albicans + PBS) and in groups with Lactobacillus cells or their supernatants. (A) Interaction of C. albicans ATCC 18804 and Lactobacillus; (B) interaction of C. albicans clinical strains (CA60 and CA230S) and Lactobacillus. The Student's $t$-test was used.

of the 28.4 strain (fivefold increase for C. albicans ATCC and threefold increase for clinical strains).

Considering the results observed by the qPCR assay, it can be confirmed that these three strains of Lactobacillus affect biofilm formation of $C$. albicans by downregulating the expression of the ALS3, HWP1, CPH1, and EFG1 genes.

\section{Discussion}

The oral cavity was evaluated for colonization of Lactobacillus spp. For this endeavor, this study investigated the presence of the genus Lactobacillus in 41 caries-free participants. It was verified that only $66 \%$ of caries-free individuals were colonized by Lactobacillus species. These data agree with Ramamurthy et al. (2014), who studied the prevalence of Lactobacillus in 50 children aged between 2 and 5 years, with 25 caries-free and 25 caries-affected children. These authors found a significant increase in the Lactobacillus colonization rate in the oral cavity from children with active caries (88\%) in comparison to caries-free children (60\%). The presence of Lactobacillus in the oral cavity is correlated with active caries or with a greater predisposition to future caries. This is due to some Lactobacillus strains having acidogenic properties and the ability to co-aggregate with other cariogenic microorganisms during tooth colonization (Ahola et al. 2002; Badet and Thebaud 2008).

Thirty Lactobacillus isolates were identified, and it was found that $L$. paracase $i$ was the most prevalent species, corresponding to $76 \%$ of the total population. In a similar study, Koll-Klais et al. (2005) isolated and identified Lactobacillus species from 15 chronic periodontitis patients and found 31 isolates; however, the most prevalent strains were Lactobacillus gasseri and Lactobacillus fermentum. Shimada et al. (2015) investigated the distribution of oral 


\section{C. albicans ATCC 18804}
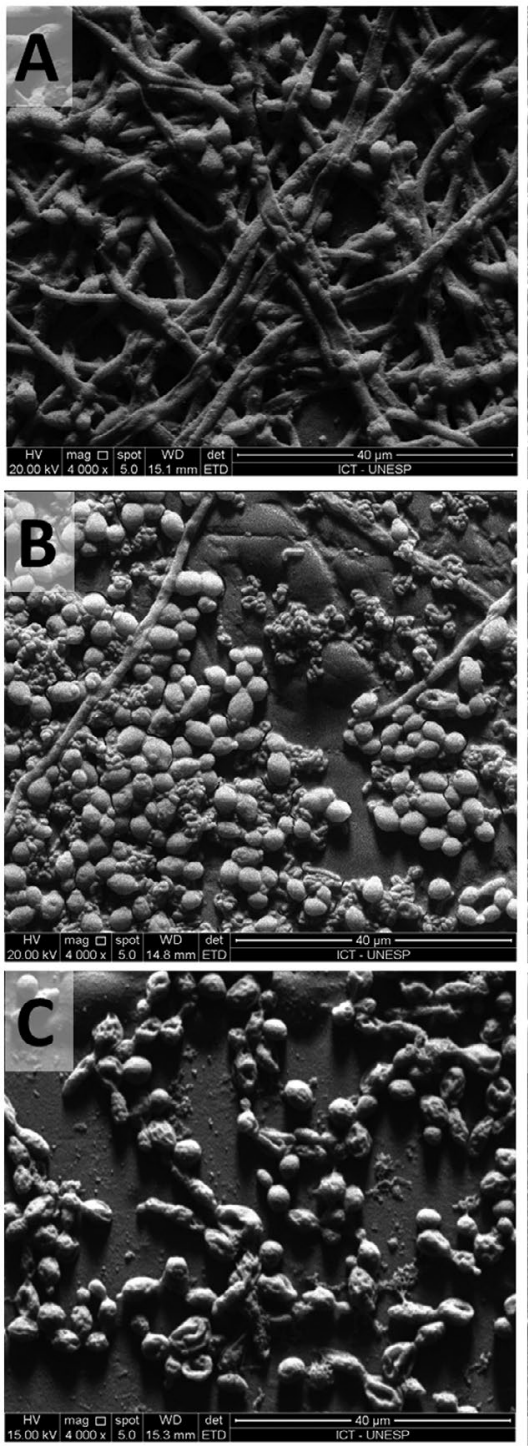

\section{C. albicans 60}
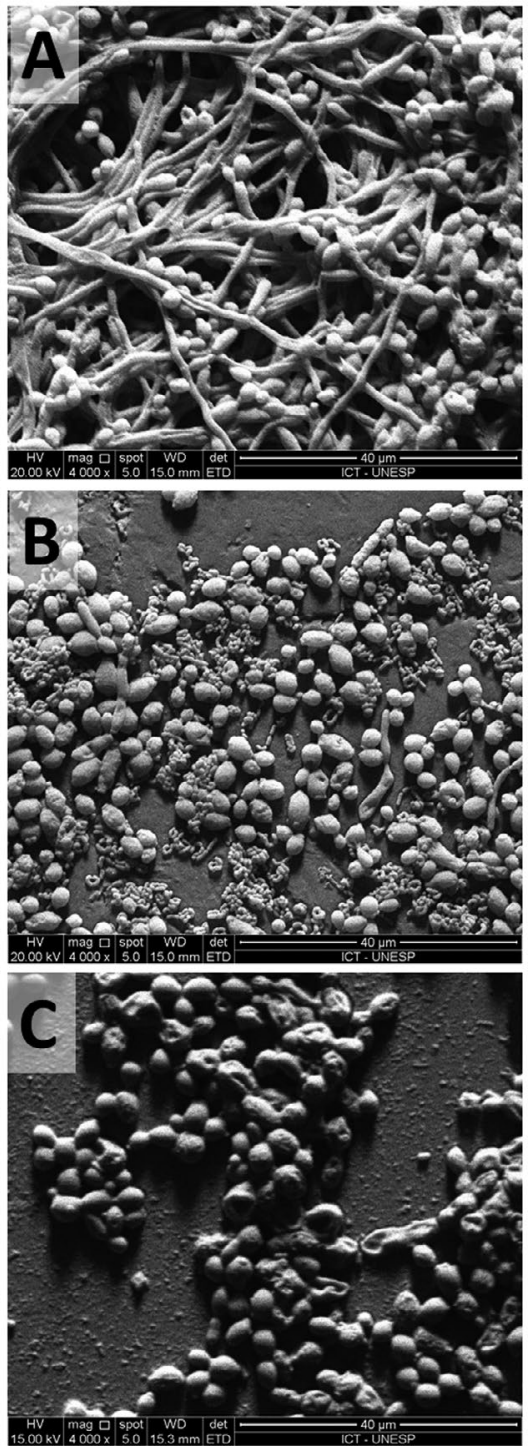

\section{C. albicans 2305}
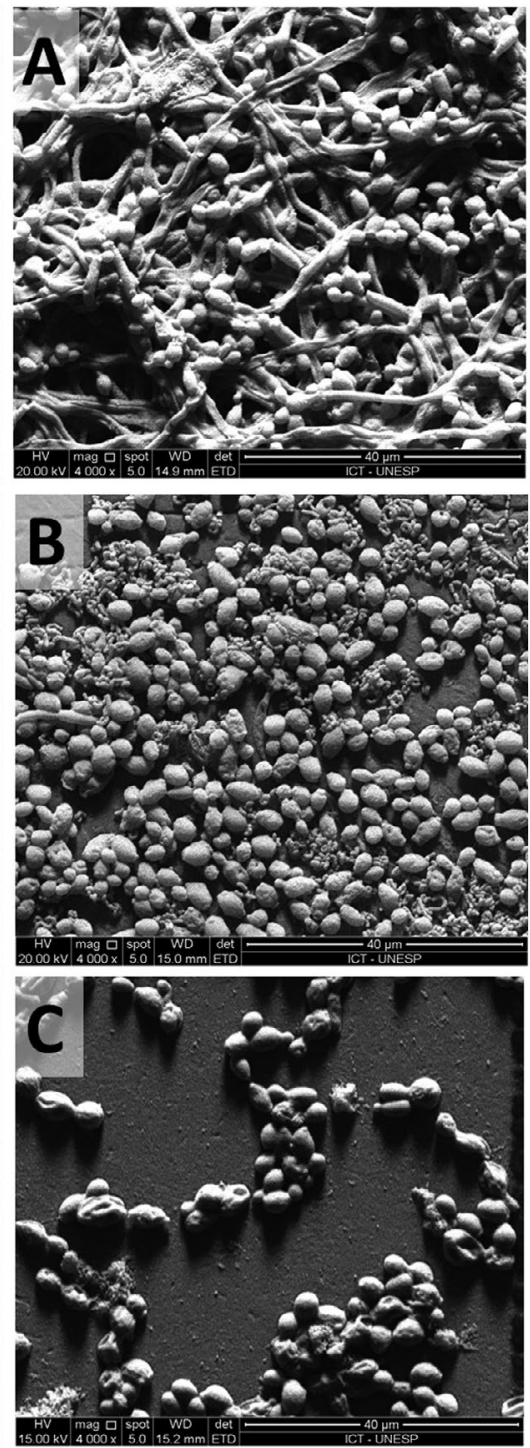

Figure 4. SEM of biofilms formed in vitro. (A) Control group of C. albicans + PBS: the presence of numerous yeast and hyphae is verified. (B) Group interaction of $C$. albicans + L. paracasei 28.4: in all mixed biofilms, it is possible to observe a reduction in the number of yeast cells and hyphae of $C$. albicans and an intimate interaction between C. albicans and Lactobacillus cells. (C) Group interaction of C. albicans + supernatant of $L$. paracasei 28.4: in all supernatant-treated biofilms, the number of yeast and hyphae of $C$. albicans are reduced, and the yeast morphology is altered. Magnification: 4,000×.

Lactobacilli among Japanese preschool children with various prevalence levels of caries. The authors verified that $L$. gasseri and L. salivarius were the most detected species in the dental cavity and carious lesions, suggesting that these species strongly contribute to the development of dental caries. The present results differ from previous reports because the strains isolated in this study came from caries-free individuals without any apparent oral disease.

To identify the isolates of Lactobacillus with the most prominent antifungal effects, the collection of isolates was subjected to interrogation in the presence of planktonic cultures and biofilms models in order to evaluate any reduction in the fungal cell population. All C. albicans strains used in this study were evaluated in association with Lactobacillus cells or with supernatant of Lactobacillus culture. Most Lactobacillus isolates exerted an antimicrobial activity against C. albicans ATCC 18804 when this yeast was placed in contact with the cells or supernatant of Lactobacillus. The percentage reductions varied between the 30 Lactobacillus strains that were tested, indicating that the antifungal effect was Lactobacillus species- and strain-specific. The number of C. albicans ATCC 18804 cells was reduced by up to $98 \%$ for planktonic cultures. 
(A) C. albicans ATCC 18804

L. rhamnosus $5.2+$ C. albicans ATCC 18804

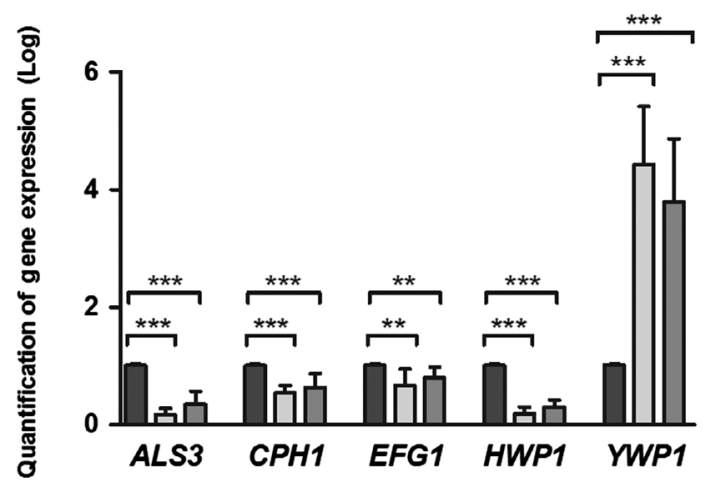

L. fermentum $20.4+$ C. albicans ATCC 18804

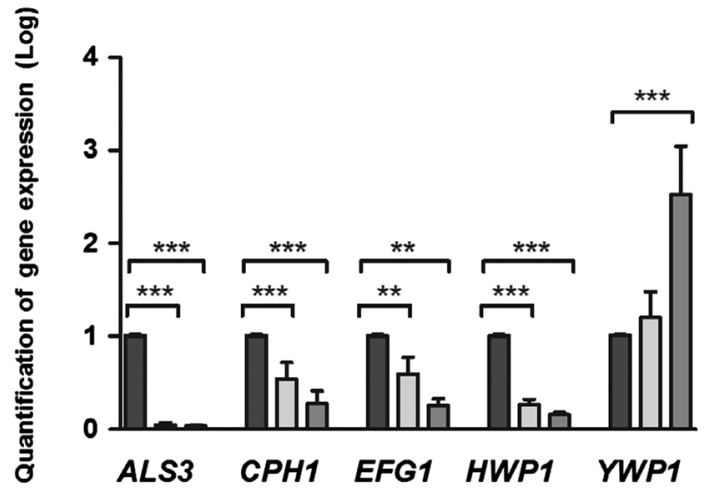

Legend of $A$ and $B$ :

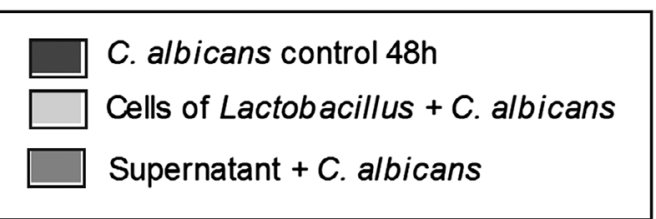

L. paracasei $28.4+$ C. albicans ATCC 18804

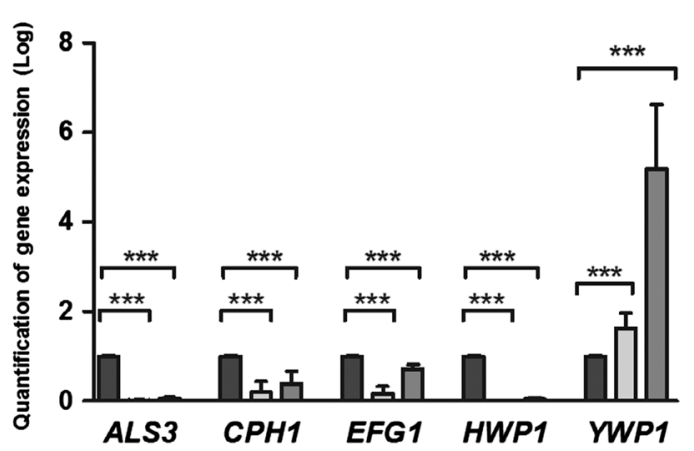

(B)

\section{C. albicans clinical strains}
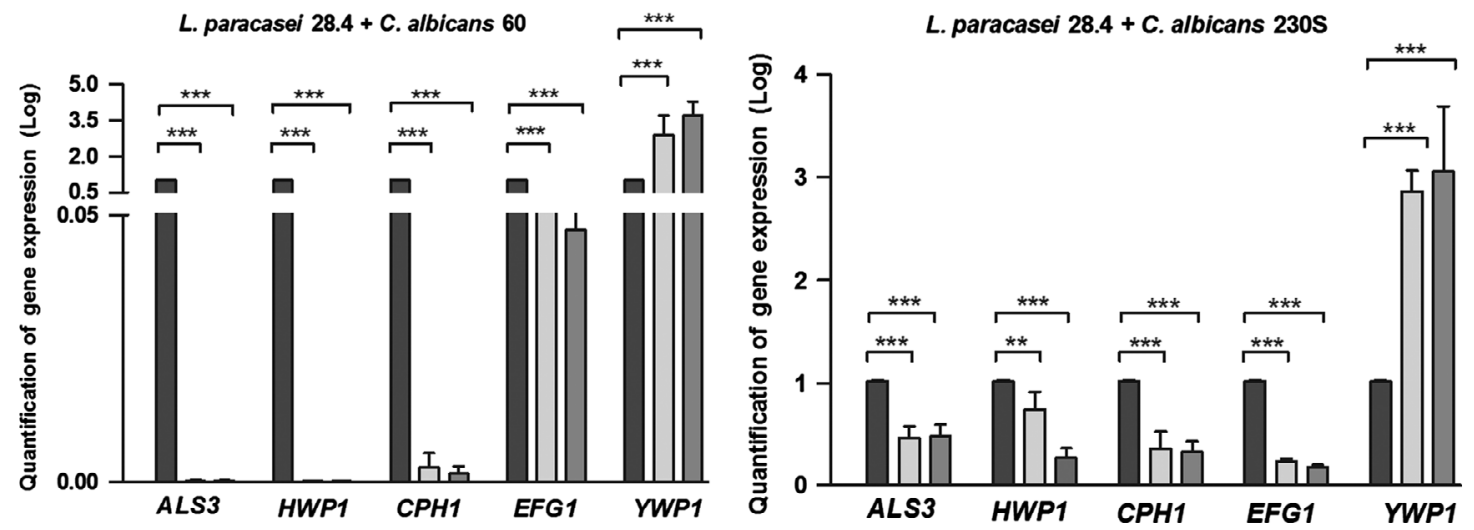

Figure 5. Relative quantification of $A L S 3, H W P 1, C P H 1, E F G 1$, and YWP1 in monotypic and mixed biofilms of $C$. albicans associated with Lactobacillus cells and their supernatants. (A) C. albicans ATCC 18804 associated with L. rhamnosus 5.2; C. albicans biofilms associated with L. fermentum 20.4; C. albicans biofilms associated with L. paracasei 28.4. (B) C. albicans strains CA60 and CA230S associated with L. paracasei 28.4. For the adhesion gene ( $A L S 3$ and $Y W P 1)$, biofilm genes (CPH1 and EFG1) and filamentation gene (HPW1): each evaluated group was normalized and compared with $C$. albicans + PBS (control). Values were expressed as the mean and SD. The Student's $t$-test was used to compare gene expression among the studied groups $(p \leq 0.05)$. ${ }^{* *}$ Indicates $p \leq 0.01 .{ }^{* *}$ Indicates $p \leq 0.0001$.

In general, the reduction in C. albicans ATCC 18804 biofilms associated with Lactobacillus cells was $78 \%$. Similar results were found by Vilela et al. (2015) who evaluated the influence of L. acidophilus ATCC 4356 cells or its supernatant on biofilm formation of C. albicans. A reduction in the number of $C$. albicans cells compared to 
the control group was observed for both groups, with a reduction of $57.5 \%$ for biofilms associated with probiotic cells and $45.1 \%$ for the corresponding supernatant. van der Mei et al. (2014) investigated biofilm formation by C. albicans in silicon pads with different strains of Lactobacillus. To form the biofilms, silicone pads were submerged in a suspension of the microbial species for $5 \mathrm{~h}$ and, after that time, the biofilm was incubated for eight days at $37^{\circ} \mathrm{C}$. The authors found a $99 \%$ reduction in C. albicans due to an association with $L$. crispatus, $98 \%$ for $L$. acidophilus and 95\% for L. paracasei.

A significant reduction in the $\mathrm{CFU} \mathrm{m} \mathrm{ml}^{-1}$ count of C. albicans ATCC 18004 with the supernatants from the Lactobacillus cultures was also observed. These data demonstrated a competitive interaction between the two tested species and suggested that the presence of substances in the bacterial metabolites converted the medium into a hostile environment for fungal biofilm development. In a recent study, Matsubara et al. (2016) evaluated the effect of L. rhamnosus, L. casei, and L. acidophilus supernatants on different stages of biofilm formation, such as after incubation for $90 \mathrm{~min}, 24 \mathrm{~h}$ and $48 \mathrm{~h}$. They found that the supernatants from the first phase of incubation $(90 \mathrm{~min})$ were unable to inhibit $C$. albicans biofilm development, and the inhibitory effect was observed only with the 24- and 48-h supernatants of the lactobacilli. Their findings strengthen the results found in the present study which show that the 24-h Lactobacillus culture supernatant was sufficient for an inhibitory effect. Moreover, these data suggest that the exometabolites produced by the Lactobacillus strains that inhibited C. albicans biofilm formation require a mature probiotic growth. In addition, the supernatant can inhibit $C$ albicans due to the high levels of organic acid produced by Lactobacillus metabolism and consequently reduce the final pH of the environment (Simark-Mattsson et al. 2009; Matsubara et al. 2016; Ribeiro et al. 2017).

Based on the CFU counting results of the C. albicans ATCC 18804 biofilms, L. rhamnosus 5.2, L. fermentum 20.4 and $L$. paracasei 28.4 were selected for subsequent experiments, as they showed the greatest ability to reduce biofilm formation by the fungus. Thus, the capacity of these bacterial strains to alter the amounts of biofilm was investigated. This analysis allowed estimation of the quantity of total biofilm cells and extracellular matrix compared to the viable cells counting method $\left(\mathrm{CFU} \mathrm{m}{ }^{-1}\right)$. In the total biomass quantification assay, a statistically significant difference was found between single C. albicans biofilms compared to mixed biofilms with Lactobacillus strains. For the mixed group with C. albicans ATCC 18804, the greatest reductions were achieved by $L$. paracasei 28.4 , L. rhamnosus 5.2 and L. fermentum 20.4. In the biofilms treated with the supernatant, there was no difference between the Lactobacillus strains that were used.
For the CFU count with clinical strains of C. albicans, significant differences were also observed when associated with the cells or supernatant of $L$. paracasei 28.4 . For the CA60 strain, a reduction of $80 \%$ was found in the cell group and $95 \%$ in the supernatant group, respectively. The CA230S strain was reduced by $97 \%$ when associated with L. paracasei 28.4 cells and $99 \%$ with their supernatant. Regarding the quantification of the biomass by $\mathrm{CV}$, all the groups associated with the cells or the supernatant of L. paracasei 28.4 showed significant reductions compared to the control group.

The biofilms were also evaluated by SEM analysis in which adherence of Lactobacillus strains on C. albicans yeasts was observed, showing an intimate association between these two microorganisms. In addition, it was possible to verify a reduction in the number of yeast cells and hyphae of $C$. albicans when the single biofilm was compared to the mixed biofilm for all the C. albicans strains in this study. According to the SEM images, $L$. paracasei 28.4 reduced the adhesion of $C$. albicans cells to the plastic surface, and this probably caused the reduction in the C. albicans CFU counting and total biomass assay. Biosurfactants are microbial compounds (eg exometabolites of lactobacilli) that reduce the hydrophobicity of the surface substratum and consequently alter microbial adhesion (Satpute et al. 2016; Sharma and Saharan 2016). Ceresa et al. (2015) showed that the biosurfactant produced by Lactobacillus brevis was able to reduce adhesion and biofilm formation in C. albicans by up to $90 \%$ on silicone pads. This mechanism may have acted to reduce the adhesion of C. albicans to Lactobacillus-treated biofilms in this study.

Previous studies have also demonstrated that lactobacilli could alter the architecture of C. albicans biofilms and suggested that this effect can be related to the downregulation of genes involved in biofilm formation as well as those associated with DNA replication, translation, glycolysis, and gluconeogenesis (Kohler et al. 2012; Chew et al. 2015; Matsubara et al. 2016). However, to elucidate the mechanisms involved in the reduction of biofilm formation and filamentation of $C$. albicans observed in the analyses by CFU counts, the total amount and the SEM, the present study was expanded at the level of gene expression to determine the involvement of Lactobacillus cells and corresponding supernatants on gene expression of $A L S 3$, $C P H 1, E F G 1, H W P 1$, and YWP1.

The capacity to form biofilms has been associated with the presence of transcriptional regulatory genes in C. albicans and these include the transcriptional regulators EFG1, BCR1, TEC1, NDT80, and ROB1 (Maiti et al. 2015; Gulati and Nobile 2016). Hyphal formation contributes to the overall architectural stability of the biofilm and acts as a support for yeast cells, pseudohyphae and other 
microbial cells in the context of polymicrobial biofilms. Thus, the ability to form hyphae as well as the ability of these hyphae to adhere to other cells is critical for biofilm development and maintenance (Gulati and Nobile 2016). For example, the HWP1 gene is expressed on the hyphal surface and encodes a cell wall protein; according to Fan et al. (2013), biofilms lacking this gene are prone to detachment from the abiotic substratum.

The ALS3 gene encoding a protein similar to alphaagglutinin plays an essential role in the adhesion of C. albicans and serves as an upstream regulator of both the Ras1-cAMP-Efg1 and MAPK pathways (Maiti et al. 2015). CPH1 can act in concert with another regulator of morphogenesis, EFG1, the transcription factor of the cAMPPKA pathway. The cphlefg1 $\Delta$ double mutant exhibited loss of function of almost the entire transcription machinery that regulates filamentation, and the mutant was avirulent in a candidiasis mouse model (Lo et al. 1997). Recently, CPH1 has been implicated in the maintenance of cell wall organization, pseudohyphal formation in response to oxidative stress, biofilm formation and in regulation of the pheromone response in both white and opaque phase cells (Morschhauser 2011; Srinivasa et al. 2012; Maiti et al. 2015). The YWP1 gene plays a key role in adhesion and dispersal of the yeast form in biofilms. This gene is highly expressed during exponential-phase growth and is strongly suppressed under conditions that promote filamentation. Furthermore, deletions of YWP1 results in strains with normal growth rates and morphologies, but increased adhesiveness of the yeast forms (Granger et al. 2005; Plaine et al. 2008; Noble et al. 2010; Granger 2012).

In the present expression profiles, most of the C. albicans genes that were studied (CPH1, ALS3, HWP1, and EFG1) were downregulated after exposure to Lactobacillus, either by direct cell-cell contact or via supernatants, both in the reference and clinical strains. This result can be associated with the decrease in the CFU counts, the total biomass and, consequently, the development of biofilm. These results agree with previous studies showing the ability of certain bacteria, such as Lactobacillus, to induce the downregulation of C. albicans genes (Kohler et al. 2012; James et al. 2016; Matsubara et al. 2016; Ribeiro et al. 2017).

YWP1 was the only gene regulated positively in the groups with Lactobacillus associated with reference and clinical strains of $C$. albicans. This positive regulation is due to the predominance of yeasts in the biofilms treated with Lactobacillus cells or their supernatant in comparison with the large amount of hyphae found in the control biofilm. This suggests a reduction in adhesiveness of the yeast forms and their consequent dispersion in the formed biofilm. However, the exact molecular mechanisms related to the action of Lactobacillus against C. albicans biofilms are still unclear and need to be further investigated, eg via analyses involving fractionation and the characterization of the supernatant components of Lactobacillus strains using liquid chromatography-mass spectrometry and nuclear magnetic resonance spectroscopy.

In conclusion, the findings of the present study show that L. fermentum 20.4, L. paracasei 28.4, and L. rhamnosus 5.2 decrease C. albicans ATCC 18804 biofilm formation by reducing the number of $C$. albicans cells, by inhibiting hyphal formation, and by destabilizing the biofilm architecture. These effects also occurred when only the supernatant of Lactobacillus strains was added to the C. albicans biofilms, suggesting that Lactobacillus strains can produce acids or exometabolites capable of inhibiting C. albicans growth. L. paracasei 28.4 also reduced the biofilm formed by CA60 and CA230S strains corroborating its anti-biofilm action. In addition, it was concluded that the inhibitory effects of Lactobacillus on C. albicans biofilms in this study are associated with the downregulation of the expression levels of the ALS3, HWP1,CPH1, and EFG1 genes. In summary, L. fermentum 20.4, L. paracasei 28.4, and L. rhamnosus 5.2 have the potential to be used as probiotics in the oral cavity to prevent the development of oral candidiasis.

\section{Disclosure statement}

No potential conflict of interest was reported by the authors.

\section{Funding}

This study was supported by the Fundação de Amparo à Pesquisa do Estado de São Paulo (FAPESP) [grant numbers 2013/26820-4, 2013/25181-8, 2015/09770-9]; and from the Brown/Brazil Initiative.

\section{ORCID}

Rodnei Dennis Rossoni (iD http://orcid.org/0000-0002-99773040

\section{References}

Ahola AJ, Yli-Knuuttila H, Suomalainen T, Poussa T, Ahlstrom A, Meurman JH, Korpela R. 2002. Short-term consumption of probiotic-containing cheese and its effect on dental caries risk factors. Arch Oral Biol. 47:799-804. doi: 10.1016/ S0003-9969(02)00112-7.

Alcazar-Fuoli L, Mellado E. 2014. Current status of antifungal resistance and its impact on clinical practice. Br J Haematol. 166:471-484. doi: 10.1111/bjh.2014.166.issue-4.

Badet C, Thebaud NB. 2008. Ecology of lactobacilli in the oral cavity: a review of literature. Open Microbiol J. 2:38-48. doi: 10.2174/1874285800802010038.

Barbosa JO, Rossoni RD, Vilela SF, de Alvarenga JA, Velloso Mdos S, Prata MC, Jorge AO, Junqueira JC. 2016. Streptococcus mutans can modulate biofilm formation and 
attenuate the virulence of Candida albicans. PLoS ONE. 11:e0150457. doi: 10.1371/journal.pone.0150457.

Barros PP, Ribeiro FC, Rossoni RD, Junqueira JC, Jorge AO. 2016. Influence of Candida krusei and Candida glabrata on Candida albicans gene expression in in vitro biofilms. Arch Oral Biol. 64:92-101. doi: 10.1016/j.archoralbio.2016.01.005.

de Barros PP, Rossoni RD, De Camargo Ribeiro F, Junqueira JC, Jorge AO. 2017. Temporal profile of biofilm formation, gene expression and virulence analysis in Candida albicans strains. Mycopathologia. 182:285-295. doi: 10.1007/s11046016-0088-2.

Belda-Ferre P, Alcaraz LD, Cabrera-Rubio R, Romero H, Simon-Soro A, Pignatelli M, Mira A. 2012. The oral metagenome in health and disease. ISME J. 6:46-56. doi: 10.1038/ismej.2011.85.

do Carmo MS, Noronha FM, Arruda MO, Costa EP, Bomfim MR, Monteiro AS, Ferro TA, Fernandes ES, Giron JA, Monteiro-Neto V. 2016. Lactobacillus fermentum ATCC 23271 displays in vitro inhibitory activities against Candida spp. Front Microbiol. 7:1722.

Ceresa C, Tessarolo F, Caola I, Nollo G, Cavallo M, Rinaldi M, Fracchia L. 2015. Inhibition of Candida albicans adhesion on medical-grade silicone by a Lactobacillus-derived biosurfactant. J Appl Microbiol. 118:1116-1125. doi: 10.1111/jam.2015.118.issue-5.

Chew SY, Cheah YK, Seow HF, Sandai D, Than LT. 2015. In vitro modulation of probiotic bacteria on the biofilm of Candida glabrata. Anaerobe. 34:132-138. doi: 10.1016/ j.anaerobe.2015.05.009.

Darrene LN, Cecile B. 2016. Experimental models of oral biofilms developed on inert substrates: a review of the literature. Biomed Res Int. 2016:7461047.

Fan Y, He H, Dong Y, Pan H. 2013. Hyphae-specific genes HGC1, ALS3, HWP1, and ECE1 and relevant signaling pathways in Candida albicans. Mycopathologia. 176:329335. doi: 10.1007/s11046-013-9684-6.

Grady NG, Petrof EO, Claud EC. 2016. Microbial therapeutic interventions. Semin Fetal Neonatal Med. 25:418-423.

Granger BL. 2012. Insight into the antiadhesive effect of yeast wall protein 1 of Candida albicans. Eukaryotic Cell. 11:795805. Epub 2012 Apr 17. doi: 10.1128/EC.00026-12.

Granger BL, Flenniken ML, Davis DA, Mitchell AP, Cutler JE. 2005. Yeast wall protein 1 of Candida albicans. Microbiology. 151:1631-1644. Epub 2005 May 05. doi: 10.1099/mic.0.27663-0.

Guarner F, Khan AG, Garisch J, Eliakim R, Gangl A, Thomson A, Krabshuis J, Lemair T, Kaufmann P, de Paula JA, et al. 2012. World Gastroenterology Organisation Global Guidelines: probiotics and prebiotics October 2011. J Clin Gastroenterol. 46:468-481. doi: 10.1097/MCG.0b013e3182549092.

GulatiM,NobileCJ.2016.Candidaalbicansbiofilms:development, regulation, and molecular mechanisms. Microbes Infect. 18:310-321. doi: 10.1016/j.micinf.2016.01.002.

Herbel SR, Vahjen W, Wieler LH, Guenther S. 2013. Timely approaches to identify probiotic species of the genus Lactobacillus. Gut Pathog. 5:27. doi: 10.1186/1757-4749-527.

Hnisz D, Bardet AF, Nobile CJ, Petryshyn A, Glaser W, Schöck U, Stark A, Kuchler K. 2012. A histone deacetylase adjusts transcription kinetics at coding sequences during Candida albicans morphogenesis. PLoS Genet. 8:e1003118. doi: 10.1371/journal.pgen.1003118.
James KM, MacDonald KW, Chanyi RM, Cadieux PA, Burton JP. 2016. Inhibition of Candida albicans biofilm formation and modulation of gene expression by probiotic cells and supernatant. J Med Microbiol. 65:328-336. doi: 10.1099/ jmm.0.000226.

Junqueira JC, Vilela SF, Rossoni RD, Barbosa JO, Costa AC, Rasteiro VM, Suleiman JM, Jorge AO. 2012. Oral colonization by yeasts in HIV-positive patients in Brazil. Rev Inst Med Trop Sao Paulo. 54:17-24. doi: 10.1590/S003646652012000100004.

Kohler GA, Assefa S, Reid G. 2012. Probiotic interference of Lactobacillus rhamnosus GR-1 and Lactobacillus reuteri RC14 with the opportunistic fungal pathogen Candida albicans. Infect Dis Obstet Gynecol. 2012:636474.

Koll-Klais P, Mandar R, Leibur E, Marcotte H, Hammarstrom L, Mikelsaar M. 2005. Oral lactobacilli in chronic periodontitis and periodontal health: species composition and antimicrobial activity. Oral Microbiol Immunol. 20:354-361. doi: 10.1111/omi.2005.20.issue-6.

Lin X, Chen X, Chen Y, Jiang W, Chen H. 2015. The effect of five probiotic lactobacilli strains on the growth and biofilm formation of Streptococcus mutans. Oral Dis. 21:e128-e134. doi: 10.1111/odi.2014.21.issue-1.

Livak KJ, Schmittgen TD. 2001. Analysis of relative gene expression data using real-time quantitative PCR and the 2(-Delta Delta C(T)) method. Methods. 25:402-408. doi: 10.1006/meth.2001.1262.

Lo HJ, Kohler JR, DiDomenico B, Loebenberg D, Cacciapuoti A, Fink GR. 1997. Nonfilamentous C. albicans mutants are avirulent. Cell. 90:939-949. doi: 10.1016/S00928674(00)80358-X.

Maiti P, Ghorai P, Ghosh S, Kamthan M, Tyagi RK, Datta A. 2015. Mapping of functional domains and characterization of the transcription factor Cph1 that mediate morphogenesis in Candida albicans. Fungal Genet Biol. 83:45-57. doi: 10.1016/j.fgb.2015.08.004.

Matsubara VH, Bandara HM, Mayer MP, Samaranayake LP. 2016. Probiotics as antifungals in mucosal candidiasis. Clin Infect Dis. 62:1143-1153.

Matsubara VH, Wang Y, Bandara HM, Mayer MP, Samaranayake LP. 2016. Probiotic lactobacilli inhibit early stages of Candida albicans biofilm development by reducing their growth, cell adhesion, and filamentation. Appl Microbiol Biotechnol. 100:6415-6426. Epub 2016 Apr 18. doi: 10.1007/s00253-016-7527-3.

van der Mei HC, Buijssen KJ, van der Laan BF, Ovchinnikova E, Geertsema-Doornbusch GI, Atema-Smit J, van de BeltGritter B, Busscher HJ. 2014. Voice prosthetic biofilm formation and Candida morphogenic conversions in absence and presence of different bacterial strains and species on silicone-rubber. PLoS ONE. 9:e104508. doi: 10.1371/journal.pone.0104508.

Million M, Raoult D. 2013. Species and strain specificity of Lactobacillus probiotics effect on weight regulation. Microb Pathog. 55:52-54. doi: 10.1016/j.micpath.2012.09.013.

Millsop JW, Fazel N. 2016. Oral candidiasis. Clin Dermatol. 34:487-494. doi: 10.1016/j.clindermatol.2016.02.022.

Morschhauser J. 2011. Nitrogen regulation of morphogenesis and protease secretion in Candida albicans. Int J Med Microbiol. 301:390-394. doi: 10.1016/j.ijmm.2011.04.005.

Nailis H, Kucharikova S, Ricicova M, Van Dijck P, Deforce D, Nelis H, Coenye T. 2010. Real-time PCR expression profiling 
of genes encoding potential virulence factors in Candida albicans biofilms: identification of model-dependent and -independent gene expression. BMC Microbiol. 10:114. doi: 10.1186/1471-2180-10-114.

Noble SM, French S, Kohn LA, Chen V, Johnson AD. 2010. Systematic screens of a Candida albicans homozygous deletion library decouple morphogenetic switching and pathogenicity. Nat Genet. 42:590-598. Epub 2010 Jun 15. doi: 10.1038/ng.605.

Noble SM, Gianetti BA, Witchley JN. 2017. Candida albicans cell-type switching and functional plasticity in the mammalian host. Nat Rev Microbiol. 15:96-108.

Oliveira VM, Santos SS, Silva CR, Jorge AO, Leao MV. 2016. Lactobacillus is able to alter the virulence and the sensitivity profile of Candida albicans. J Appl Microbiol. 121:17371744. doi: 10.1111/jam.2016.121.issue-6.

Olle B. 2013. Medicines from microbiota. Nat Biotechnol. 31:309-315. doi: 10.1038/nbt.2548.

Orsi CF, Sabia C, Ardizzoni A, Colombari B, Neglia RG, Peppoloni S, Morace G, Blasi E. 2014. Inhibitory effects of different lactobacilli on Candida albicans hyphal formation and biofilm development. J Biol Regul Homeost Agents. 28:743-752.

Peeters E, Nelis HJ, Coenye T. 2008. Comparison of multiple methods for quantification of microbial biofilms grown in microtiter plates. J Microbiol Methods. 72:157-165. doi: 10.1016/j.mimet.2007.11.010.

Plaine A, Walker L, Da Costa G, Mora-Montes HM, McKinnon A, Gow NA, Gaillardin C, Munro CA, Richard ML. 2008. Functional analysis of Candida albicans GPI-anchored proteins: roles in cell wall integrity and caspofungin sensitivity. Fungal Genet Biol. 45:1404-1414. Epub 2008 Sep 04. doi: 10.1016/j.fgb.2008.08.003.

Ramamurthy PH, Swamy HS, Bennete F, Rohini M, Nagarathnamma T. 2014. Relationship between severeearly childhood caries, salivary mutans streptococci, and lactobacilli in preschool children of low socioeconomic status in Bengaluru city. J Indian Soc Pedod Prev Dent. 32:44-47. doi: 10.4103/0970-4388.127054.

Ribeiro FC, de Barros PP, Rossoni RD, Junqueira JC, Jorge AO. 2017. Lactobacillus rhamnosus inhibits Candida albicans virulence factors in vitro and modulates immune system in Galleria mellonella. J Appl Microbiol. 122:201-211. doi: 10.1111/jam.2017.122.issue-1.

Rivera-Espinoza Y, Gallardo-Navarro Y. 2010. Non-dairy probiotic products. Food Microbiol. 27:1-11. doi: 10.1016/j. fm.2008.06.008.

Salas-Jara MJ, Ilabaca A, Vega M, Garcia A. 2016. Biofilm forming Lactobacillus: new challenges for the development of probiotics. Microorganisms. 20:4-35.

Satpute SK, Kulkarni GR, Banpurkar AG, Banat IM, Mone NS, Patil RH, Cameotra SS. 2016. Biosurfactant/s from Lactobacilli species: Properties, challenges and potential biomedical applications. J Basic Microbiol. 56:1140-1158. doi: 10.1002/jobm.v56.11.

Schwendicke F, Korte F, Dorfer CE, Kneist S, Fawzy El-Sayed K, Paris S. 2017. Inhibition of Streptococcus mutans growth and biofilm formation by probiotics in vitro. Caries Res. 51:87-95. doi: 10.1159/000452960.

Sellam A, Whiteway M. 2016. Recent advances on Candida albicans biology and virulence. F1000Res. 5:2582. doi: 10.12688/f1000research.

Shanahan F, Dinan TG, Ross P, Hill C. 2012. Probiotics in transition. Clin Gastroenterol Hepatol. 10:1220-1224. doi: 10.1016/j.cgh.2012.09.020.

Sharma D, Saharan BS. 2016. Functional characterization of biomedical potential of biosurfactant produced by Lactobacillus helveticus. Biotechnol Rep (Amst). 11:27-35. doi: 10.1016/j.btre.2016.05.001.

Shimada A, Noda M, Matoba Y, Kumagai T, Kozai K, Sugiyama M. 2015. Oral lactic acid bacteria related to the occurrence and/or progression of dental caries in Japanese preschool children. Biosci Microbiota Food Health. 34:29-36. doi: 10.12938/bmfh.2014-015.

da Silva Dantas A, Lee KK, Raziunaite I, Schaefer K, Wagener J, Yadav B, Gow NA. 2016. Cell biology of Candida albicanshost interactions. Curr Opin Microbiol. 34:111-118. doi: 10.1016/j.mib.2016.08.006

Simark-Mattsson C, Emilson CG, Hakansson EG, Jacobsson C, Roos K, Holm S. 2007. Lactobacillus-mediated interference of mutans streptococci in caries-free $v s$. cariesactive subjects. Eur J Oral Sci. 115:308-314. doi: 10.1111/ eos.2007.115.issue-4.

Simark-Mattsson C, Jonsson R, Emilson CG, Roos K. 2009. Final $\mathrm{pH}$ affects the interference capacity of naturally occurring oral Lactobacillus strains against mutans streptococci. Arch Oral Biol. 54:602-607. doi: 10.1016/ j.archoralbio.2009.03.005.

Song Y, Kato N, Liu C, Matsumiya Y, Kato H, Watanabe K. 2000. Rapid identification of 11 human intestinal Lactobacillus species by multiplex PCR assays using group- and speciesspecific primers derived from the 16S-23S rRNA intergenic spacer region and its flanking $23 \mathrm{~S}$ rRNA. FEMS Microbiol Lett. 187:167-173.

Srinivasa K, Kim J, Yee S, Kim W, Choi W. 2012. A MAP kinase pathway is implicated in the pseudohyphal induction by hydrogen peroxide in Candica albicans. Mol Cells. 33:183193. doi: 10.1007/s10059-012-2244-y.

Thein ZM, Samaranayake YH, Samaranayake LP. 2006. Effect of oral bacteria on growth and survival of Candida albicans biofilms. Arch Oral Biol. 51:672-680. doi: 10.1016/ j.archoralbio.2006.02.005.

Tsui C, Kong EF, Jabra-Rizk MA. 2016. Pathogenesis of Candida albicans biofilm. Pathog Dis. 74:ftw018.

Vilela SF, Barbosa JO, Rossoni RD, Santos JD, Prata MC, Anbinder AL, Jorge AO, Junqueira JC. 2015. Lactobacillus acidophilus ATCC 4356 inhibits biofilm formation by C. albicans and attenuates the experimental candidiasis in Galleria mellonella. Virulence. 6:29-39. doi: 10.4161/21505594.2014.981486.

Wannun P, Piwat S, Teanpaisan R. 2016. Purification, characterization, and optimum conditions of Fermencin SD11, a bacteriocin produced by human orally Lactobacillus fermentum SD11. Appl Biochem Biotechnol. 179:572-582. doi: 10.1007/s12010-016-2014-y. 